\title{
Looking Longer: The Thickening of Time Amidst Second-wave Digital Culture
}

\author{
BENJAMIN J. SMITH \\ Tulane University
}

This paper responds to the session theme, Becoming Digital, in two ways: (1) By recognizing a cultural shift in the use of digital tools toward precise aesthetic ambitions, and (2) by analyzing a transitional body of work by the Los Angeles architect and educator, Coy Howard. The selection of Howard's work from his $\mathbf{2 0 1 0}$ exhibition at the Southern California Institute of Architecture, From Hand to Mouse, and his subsequent book from 2015, The Thickening of Time, demonstrate a critical moment, not only in the change in media of an architect predominantly known for his analog representational practices, but also within the context of digital image production in architecture that favors aesthetic results over techniques. The view presented observes this body of Howard's work as one example of an intermediate case between two phases of digital production in architecture, connecting it to experimentation in digital formalisms and the drive to wield digital tools with rigorous sensibility. To do this, the paper couples an historical/interpretive research methodology with logical argumentation, relying on texts from aesthetic analysis and philosophy to situate qualitative descriptions of Howard's work within a disciplinary context of contemporary architectural representation. Graham Harman's philosophy of Object-Oriented Ontology and Bill Brown's conceptualization of Thing Theory are leveraged to explore the aesthetic qualities of mystery and alterity inherent to Howard's aesthetic goals. In an era marked by rapid image consumption through social media, the positioning of this work, which was first exhibited only two days after Instagram went live, presents an historically significant moment to question the culture of attention toward the influence of images and the relevance of digital media in exhibitions and books.

\section{PAPER}

Becoming digital, or the ontology of digital tools in contemporary architecture, suggests developing frameworks to consider decision-making in the post-digital era. Significant to this position underscores the role of digital production percolating at schools and in a host of recent practices. The term post-digital currently lacks clear definition, and questions remain whether post-digital means architecture has moved past digital tools, or whether it means architecture has found alternatives for digital production as a second-wave digital culture, or what Mario Carpo has claimed as the "second digital turn." ${ }^{\text {"B }}$ Between the late 20th century and the contemporary moment, architecture has seen a departure from virtuoso geometries and parametric algorithms, to equally formal results, but results that appear ascetic and compositional through abstraction.
Architects and architecture schools are not slowing their use of digital tools, but they are re-imagining and re-tooling their outputs with them. Arguing for a second wave digital culture, this paper positions emerging critical practices with digital tools that reach beyond technical virtuosity and claims that what drives recent modes of production relates to clear aesthetic questions defining design solutions. In positioning this transitional moment between digital complexity and digital abstraction a body of work by Coy Howard, from his book, The Thickening of Time, presents in intermediate case between the dialectic of early digital practices and today, where an experienced architect not only became digital, but critiqued digital culture through his results. Rather than an exploration of what digital tools could do, Howard focused on a tool's control, driven by the visual communication of precise aesthetic effects.

Something about Coy Howard going digital is like Bob Dylan going electric. Howard's 2015 book, The Thickening of Time (figure 1), demonstrates his transition in media from the tactility of his artifacts of the 1970s and 1980s that cemented his position as the LA School's materiality expert. Coming of age in 1970s Los Angeles, Howard's oeuvre continues to provoke curiosity through its seduction and vitality, elegance and savagery. Mottled graphite in the Hauser (1977) and Boudov (1977) perspectives brood. Mixed media encaustics of the low bas-relief Drawls (1970s-1980s) vacillate with perspicuity-pushing and pulling forms, smoothing surfaces. Joinery of the Palevsky living room table (1984), nicknamed Cross Bow, orchestrates Macassar ebony, purpleheart, bronze, and glass. Reluctant to name his work, Howard prefers enigmatic titles to avoid labels which he considers "a fallacy of misplaced concreteness." ${ }^{2}$ Known for performing lectures, whether inside refrigerator boxes or using props like toy trains, Howard insists on designing for experience, regardless of media.

Nearly a decade ago marked Howard's first significant foray into digital media with two back-to-back exhibitions at the $\mathrm{SCl}$-Arc Gallery in 2010, Part I - From Hand to Mouse, From Furniture to Architecture and Part II - Whispers and Echoes. ${ }^{3}$ The first exhibition, From Hand to Mouse, included renditions of the images used in his book, featuring a series of 50 digital renderings concealed behind lavender veils and a selection of his earlier furniture pieces. ${ }^{4}$ The second, Whispers and Echoes, included photographic images and text on the galley walls and partially covered freestanding objects on a floor covered in red sawdust. At the opening for Whispers and Echoes, Howard and then $\mathrm{SCl}$ Arc Director, Eric Owen Moss, discussed digital tools. Howard 
critiqued his perception of a trend at that time that used digital tools to produce single-surface architecture, which he argued reduced the "range and diversity" of experience. ${ }^{5}$ In his exhibition, focus steered away from process and toward its results. During the conversation with Moss, Howard expressed the exhibition's ambition from the aesthetic position of mystery. "I believe mystery is the grounds of experience. I believe that manifoldness is richer than singularity or exclusiveness." ${ }^{16}$ Throughout his career, qualities of mystery and manifoldness drive Howard's work. Instead of adhering to a point of view about creative practice predicated by results from a specific media, the motive behind Howard's work explores the aesthetic quality of strangeness to instigate the imaginations of his audience.

Howard has described a set of qualities a work must possess for it to be interesting. They are: differentiation, movement, manifoldness, mystery, and a sense of being a totality. Howard described these qualities as they related to a creative work in an interview:

It has to differentiate itself from everything else. It has to have a sense of movement, and movement is visual movement, which is this gestural stream, and cognitive movement. It has to essentially make you think and re-conceptualize. It has to have manifoldness. That is multiplicities of qualities, and manifoldness is what, in some cases, generates a sense of movement. It has to have mystery, [meaning] that ... understanding [a creative work's] existence is more about not knowing it than it is about knowing [it].... And then lastly, ... it has such a sense of totality through this manifoldness and mystery that it seems to suggest the potential for generating a whole body of other [considerations]. . . . I'm always judging everything by those standards. ${ }^{7}$

Over Howard's career he developed his understanding of these qualities. He described how something felt if a work was spectacular in mystery but lacking in manifoldness. When asked this he replied, “it just basically means that [the mystery] can't last very long." 8 Through his work he cultivates awareness to these properties and seeks to find balance with them. These are relative terms and for Howard to use them requires a relationship to the context under investigation, including the context of sensibility. The balance Howard learned exists between logic and introspection, the rational and the poetic, and builds his view of architecture as an epiphenomenon-a byproduct that emerges through feeling and emotion. Introducing digital media into his repertoire of visualization did not change his sensibility, but exposed new opportunities to produce the effects of interesting and introspective architecture.

Howard teaches at the Southern California Institute of Architecture, a school known for its novel use of software and new technologies. His approach to digital tools cautions that most work relying on fashionable software looks like the

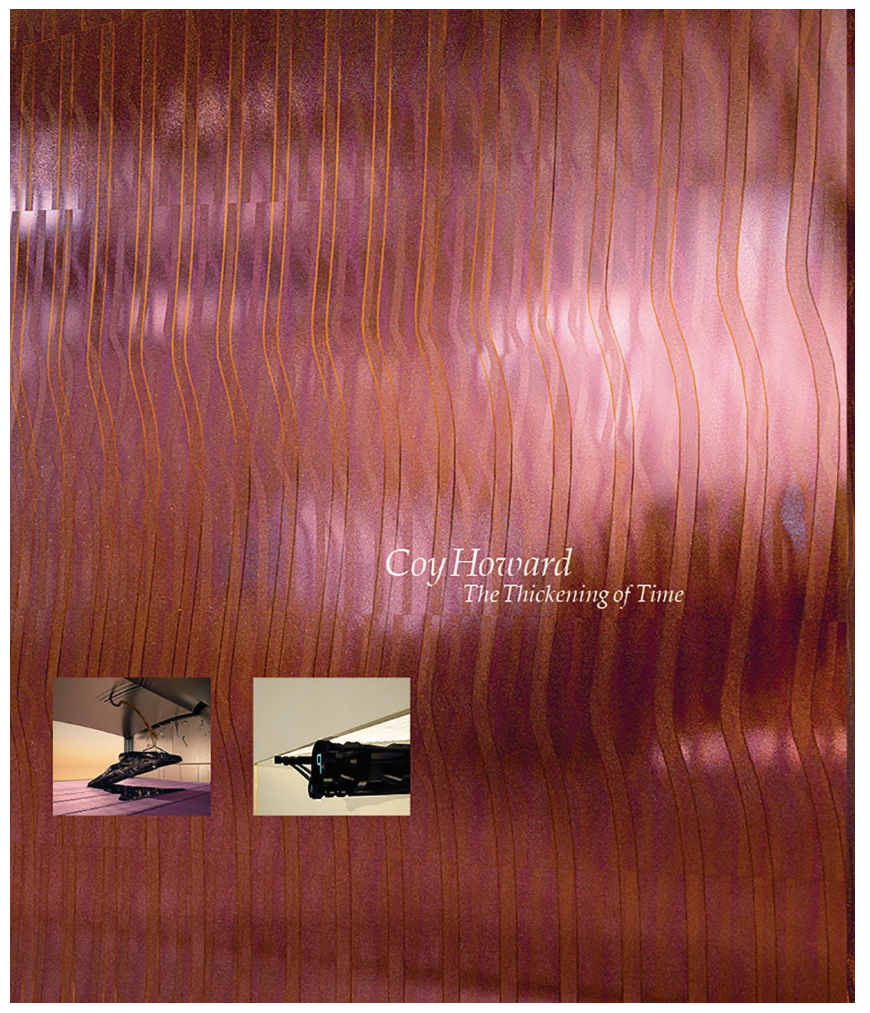

Figure 1. Coy Howard, Book Jacket, Pink \& Yellow, Villa No. 5, "The Thickening of Time," 2014. Image courtesy of Coy Howard.

software it came from. In 2001, he said work should not look like it came from a computer. ${ }^{9}$ He explained, "if you look at [something] and say 'that's a computer drawing,' you've dismissed $99 \%$ of what's there. ${ }^{\prime 10}$ In Howard's critique he does not mean to not use digital tools, what he means is that the tool of production should not drive results. Howard's claim questions the value of a work tethered to its method of production and suggests that method becomes the evaluative criteria leading toward a solution, rather than its result.

Howard's ideas about aesthetics suggest that the tool does not matter, but rather the idea matters, or the effects produced by the architectural artifact matter, and that what we know about something affects our experience of a work. If the tool generating results cannot be separated from its experience, it can distract its audience from a work's objective. For example, in the mid-2000s architectural projects began to use parameters built into Grasshopper scripts for façade panelization. In work such as this, the tool of production easily becomes recognizable if the techniques lack control or clear objectives.

According to Howard, the best architecture cannot be photographed. ${ }^{11}$ It is ironic that the projects in The Thickening of Time consist of nothing other than simulated photographs of digital models. However, Howard's critique suggests the impossibility of depicting architectural experience in a single photograph. Instead, Howard's book relies on scrutiny and reason between a series of images to reveal, or in his words, "presence," the 


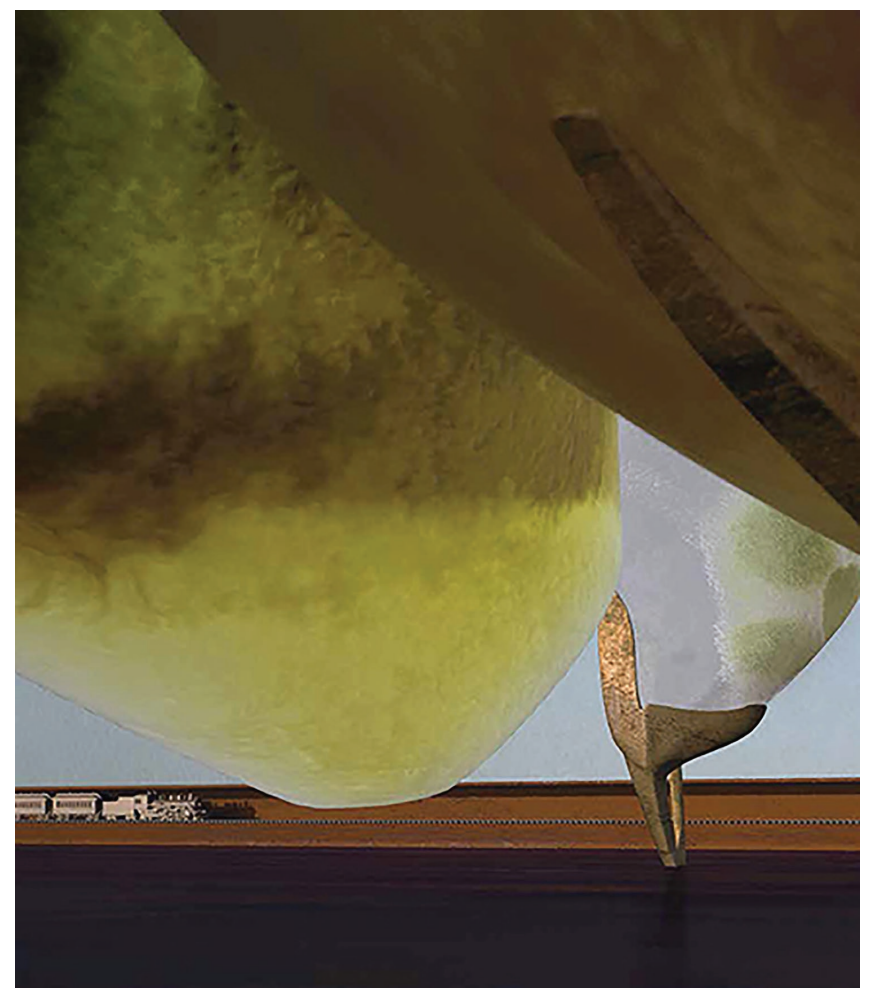

Figure 2. Coy Howard, Amber, Villa No. 2, 2014. Image courtesy of Coy Howard.

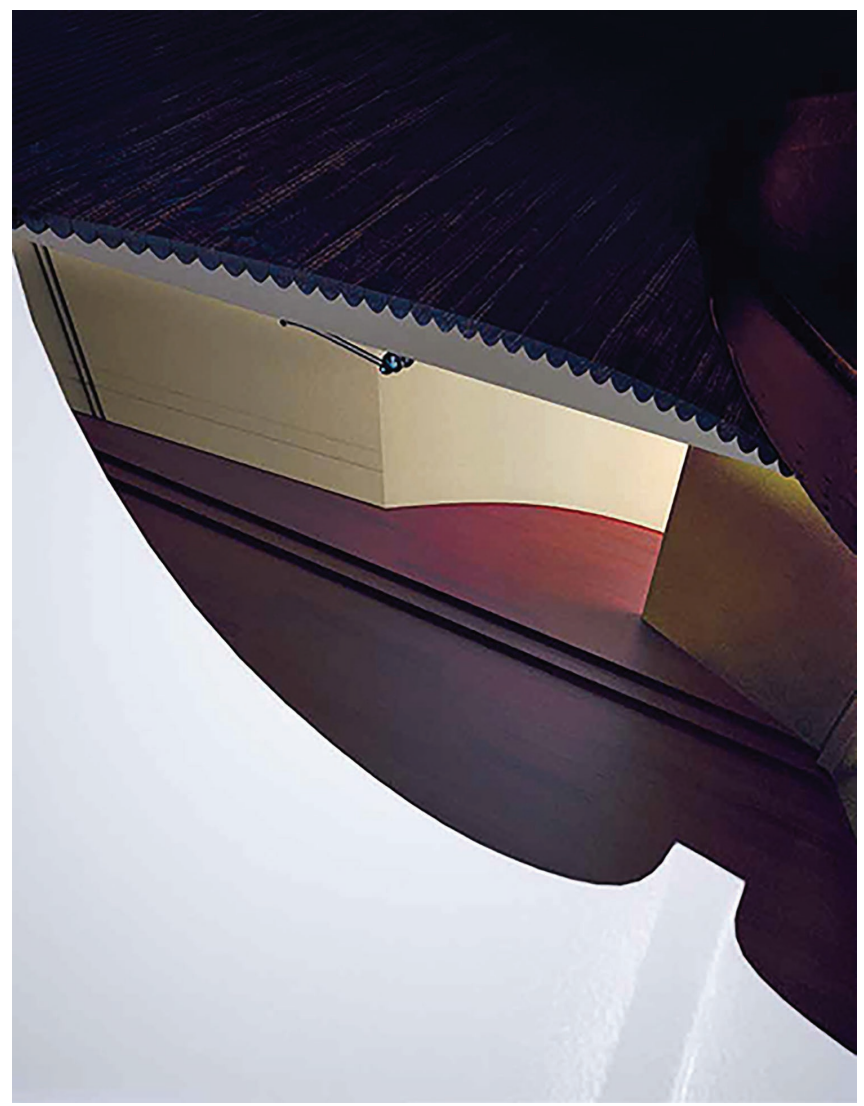

Figure 4. Coy Howard, Red, Villa No. 3. Image courtesy of Coy Howard.

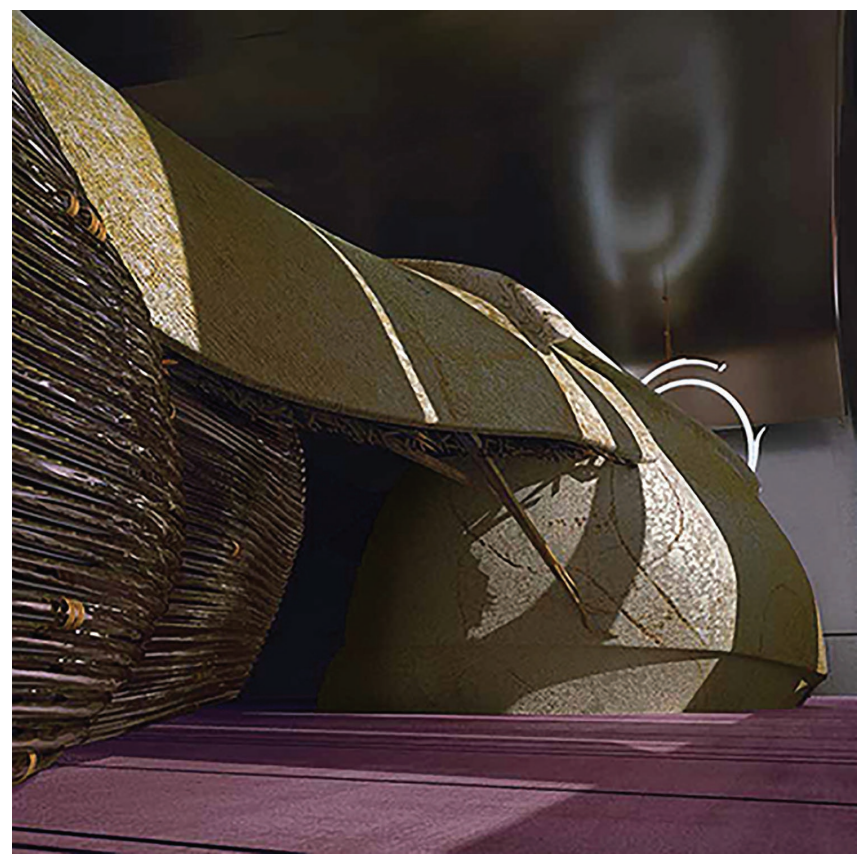

Figure 3. Coy Howard, Pink \& Yellow, Villa No. 5, 2014. Image courtesy of Coy Howard.

architecture through the imaginative experience of his audience. Three sets of renderings organize the majority of the book: Amber, Villa No. 2; Pink \& Yellow, Villa No. 5; and Red, Villa No. 3 (figures 2-4). Never given a clear elevation, section, or plan-only sideways glances, views of details, and intimate perspectives describe the villas. Representations shape narratives tangling the villa as a trope. Each page reveals metonyms, or signifies artifacts, or flashes aspects. The villas occur between observations. Howard denies transparent visualization, pushing ambiguity for semblance. With fragments to ascertain a whole, Howard initiates the personal gestalt of the viewer through objects and scenes, making the viewer/reader the subject by estranging the object. Rather than attempting to depict, the images in The Thickening of Time engender latent qualities of architectural experience.

Essays from Jeff Kipnis, George Rand, and Larry Rouch grapple with this, exposing psychological effects latent in Howard's work. Kipnis' observation detects indeterminate vacancy transfigured by piercing forms. Rand's mixture of sources reconciles the fantasy of entropy. Rouch finds poetic symbols through Howard's digital portals. An underlying supposition of the texts demonstrates Howard's work to invigorate a contemporary phenomenological discussion through digital tools.

Without words to instigate a narrative, Howard activates forms, textures, and color palettes. Close-ups and distant perspectives offer glimpses of architectural objects. Shadows smear across the page. Light materializes-veiling forms, washing surfaces, softening edges, and plumping volumes. 
Without hiding the fact of digital production, Howard couples Dziga Vertov-esque views and multiple scales of legibility within the perspectives. He charges the viewer to rethink conventions of architectural communication through the exploration of images. Howard imbues attitude into a rendering-destabilizing representation's status quo by denying what a rendering ought to do. Meaning to provoke, Howard teases the viewer to turn the next page only to find more obfuscation, without resolving a definitive overall form. Though possible, constructing a plan of the Villas would defeat the intention.

In reading the intricate compositions, forms jump from scene to scene, where the design's completion becomes resolved in the viewers imagination. Dynamization of space and spatialization of time, terms about cinema by Erwin Panofsky, apply to the experience of seeing images where "not only [objects] move in space, but space itself does, approaching, receding, turning, dissolving and recrystallizing as it appears through the controlled locomotion and focusing of the camera and through the cutting and editing of the various shots." ${ }^{12}$ In viewing Howard's Villas, the framing and editing fuels the gaps between the pages. Flipping back and forth through the book, it feels as if Howard attempts to capture Barthe's notion of "rereading ... [that] recaptures a mythic time." ${ }^{\text {"13 }}$ Fragments and fractions of delirious forms with delirious materials-bind the singular images in a temporal sequence.

Very much a physical object, the book's dust jacket, of predominantly marsala gradients compliment the indigo of a silk cover. The subtle texture of embossed lettering contrasts the cover's otherwise smooth matte finish. Opening the cover reveals eggplant endpaper and raspberry head and tailbands. The ascetic composition of one image per spread, set onto satin paper, leaves only the page number on the verso and the rendering on the recto. Occasionally, double-spread views break the consistent rhythm. The text, three essays, all occur at the beginning of the book, printed in italic serifs. The title, The Thickening of Time, evokes an objective correlative, providing a temporal framework that establishes a structure to engage the book's diversity of composed images.

Centripetal and centrifugal-two words from the epigramimply elongated and focused qualities, suggesting that thickening time does not fill duration, but grips perception. In this poetic relationship to time, Howard's work relates to the Russian filmmaker Andrey Tarkovsky. In Sculpting in Time, Tarkovsky writes, "poetry is an awareness of the world, a particular way of relating to reality. So poetry becomes a philosophy to guide a [person] throughout [her/his] life."14 Tarkovsky's characteristic long takes allow the subject's relation to her/his/its reality to unfold as the audience endures the scene. Howard uses duration with similar intensity. His images strike and vanish, but linger.
The proposition underlying Howard's approach suggests two similar ways to consider his results: (1) mystery as a quality without categories, or (2) the precision of ambiguity to establish alterity. Aesthetic theories from Graham Harman and Bill Brown help to more clearly formulate these distinctions.

Harman writes his 2013 essay, "Objects and Architecture," positing "object-oriented philosophy [as] the non-relationality of things." ${ }^{15}$ Harman's essay presented a polemical response to Patrik Schumacher's Parametricism, faulting its "view of reality as a system of communications [that] treats objects as too indeterminate-as mere fictions hiding behind a communicational system in which all specific elements are completely defined without remainder." ${ }^{\prime 16}$ Instead Harman calls for architectural objects "that do not communicate entirely with their surroundings, but leave some inscrutable surplus in reserve. ${ }^{117}$ His essay argues for a new model to consider aesthetic engagement with architectural objects, claiming, "there must always be something about the object that is in excess of its qualities and relations." ${ }^{\prime 18}$ Harman suggests not only the plausibility, but also the desirability of architectural objects to become non-sequiturs, or objects that appear out of place and resist contextual definition.

As an alternative to Harman, Bill Brown's 2001 articulation of a thing theory posits the alterity of quasi-objects, referencing Bruno Latour and Michel Serres, from a conceptual perspective on an object's, or thing's, aesthetic character. ${ }^{19}$ Brown, like Harman, considers the value of an apparent strangeness of things, but points out "the question is less about what things are for a given society than about what claims on your attention and on your action are made on behalf of things." Not only is thingness perceived but it mobilizes engagement. Brown claims that transitional moments with media instigate alternative frameworks to encounter aesthetics. "New media ... each in its way newly mediates the relation between people and objects, each precipitates distance and proximity. ${ }^{\prime 20}$ Brown's inclusion of proximity presents a conceptual difference between thing theory and an object-oriented philosophy. The former recognizes a relationship between an object, or thing, and its viewer, even if the distance is vast, whereas the latter seeks to abolish any discernable relationship. The things within Howard's renderings for the exhibition, and in his subsequent book, seek transcendence as objects through their mystery, not as non-sequiturs, but as objects with proximity to a viewer to motivate actions for imaginative reception.

In an era of post digital virtuosity architects battle the hum of influence. Designers glide between the latest software and references. In a culture of pervasive coolness and pervasive anathema, Coy Howard's work advocates to pause and look, and to see and think - through manipulating the conventions of threshold, boundary, and aperture. The Villas stir participation with archetypes and resonate materially. Howard says, "Make it strange. Not new, ${ }^{\prime 21}$ and offers an opportunity for architecture to engage its audience through an act of co-creation. 


\section{ENDNOTES}

1 Mario Carpo, The Second Digital Turn: Design Beyond Intelligence (Cambridge, MA: The MIT Press, 2017), Kindle edition.

2 Ronald Desmet and Andrew David Irvine, "Alfred North Whitehead," The Stanford Encyclopedia of Philosophy (Fall 2018 Edition), Edward N. Zalta, ed., accessed October 3, 2019. https://plato.stanford.edu/archives/fall2018/ entries/whitehead/.

3 The coincidence of the first exhibition, opening on October 8,2010, just two days after Instagram went live, situates Howard's work at a pivotal moment in the history of image production, image dissemination, and image consumption in architecture. His eventual titling of the book, Coy Howard, The Thickening of Time (Los Angeles: SCI-ARC Press, 2015), suggests, whether Howard was consciously aware, or subconsciously intimating, that the culture of attention toward architectural imaging and representation was rapidly changing.

4 Eric Chavkin, "Review: Coy Howard Exhibition," posted to Archinect, October 23, 2010. https://archinect.com/news/article/102057/ review-coy-howard-exhibition.

5 SCl-Arc Mdeia Archive, "Coy Howard: Exhibition Discussion (November 19 2010)," YouTube video, 1:04:06, September 5, 2017. https://www.youtube.com/ watch?v=WvGTAX4Vcgs.

$6 \mathrm{SCl}$-Arc Mdeia Archive, "Coy Howard: Exhibition Discussion (November 19, 2010)."

7 Coy Howard, interview with Benjamin J. Smith, June 19, 2013.

8 Coy Howard, interview with Benjamin J. Smith.

9 Aino Paasonen, "Coy Howard," in The Architect, Poetry, + the City: SCI ARC Faculty Interviews, ed., Aino Paasonen (Los Angeles: SCl-Arc Public Access Press \#40, 2001), 101.

10 Paasonen, 101

11 Coy Howard in conversation with Benjamin J. Smith, 2007.

12 Erwin Panosky, "Style and Medium in the Motion Pictures," in Film Theory and Criticism, 6th Ed, eds., Leo Baudry and Marshall Cohen (Oxford: Oxford University Press, 2004), 291-292.

13 Roland Barthes, S/Z, trans,. Richard Miller (New York: Hill and Wang, 1974), 16.

14 Andrey Tarkovsky, Sculpting in Time, trans., Kitty Huner-Blair (Austin: University of Texas Press, 1987), 21.

15 Graham Harman, “Objects and Architecture," in Archilab 2013: Naturalizing Architecture (Orleans: Hyx, 2013), 234

16 Harman., 237.

17 Harman, 242

18 Harman, 242.

19 Bill Brown, "Thing Theory," Critical Inquiry 28, no. 1 (Autumn 2001): 12

20 Brown, 16.

21 Coy Howard in conversation with Benjamin J. Smith, April 10, 2015. 